\title{
Supporting Factors for the Implementation of Mobile Learning for Elementary School Students Using an Authentic Approach and Real-World Activities
}

\author{
https://doi.org/10.3991/ijim.v16i05.26551 \\ Abna Hidayati ${ }^{(凶)}$, Alwen Bentri, Eldarni \\ Faculty of Education, Universitas Negeri Padang, Padang, Indonesia \\ abnahidayati@fip.unp.ac.id
}

\begin{abstract}
This research aims to determine the supporting factors for the implementation of mobile learning for elementary school students using an authentic approach and real-world activities. The methods used are significant because, various approaches toward mobile learning have been utilized in elementary school, particularly in the online learning. This research used a descriptive quantitative method and the participants include 26 randomly selected students. The required data were the characteristics of students in online learning, which were obtained from the instruments in questionnaires and test sheet form. The questionnaires were intended to determine the students' characteristics, while the question test was needed to obtain their initial abilities. The data collection was conducted by home visit and WhatsApp application. The type of data analysis was factorial, using the smartPLS application. The results showed that the supporting factors for the implementation of mobile learning, using authentic approach and real-world activities were as follows: 1) the students' prior concrete and logical thinking skills, 2) low entry behaviour of students, and 3) visual and auditory learning styles, which affect the meaningful learning. Furthermore, this suggests that teachers and administrators should create mobile learning exercises, which support authentic learning and real-world activities.
\end{abstract}

Keywords - mobile learning, entry behaviour, learning style, authentic learning, real-world activities

\section{Introduction}

The COVID-19 pandemic and the trend of learning digital skills, necessitate fundamental changes in the learning design and activity within the school environment. Presently, the fundamental changes are found to be rapidly increasing in learning activities, interaction systems, school administrators and teacher's role [1]. The current role of school devices has changed from administration procedure to learning management system that supports student activities [2]. Moreover, the pattern of learning has changed from the original or conventional design in the classroom to the online learning. The implementation of online learning needs to consider the characteristics 
of students, in order to achieve an optimal learning process [2]. However, online learning has been ineffective during the pandemic. According to a survey, 92\% of students had problems and 38\% admitted to not receiving teachers' guidance. The remaining students lacked learning resources as well as facilities and were not acquainted with their parents, resulting in less acquired knowledge. Based on this condition, only $60 \%$ of students managed to master their competencies. Additionally, a survey conducted by UNICEF reported that $66 \%$ of 40 thousand Indonesian students were uncomfortable with online learning, due to the lack of interaction with teachers, and they did not achieve the expected competencies. [3][4]. Therefore, it is critical to create an online learning design that fulfills the needs of students.

The learning process is essentially a series of designed activities for students, both in face-to-face and online learning. In online learning, students' interaction is optimized with designed academic work according to their needs. These learning resources are available on the internet and used as needed [1]. Teachers take the advantage of digital learning instruments which are available on the internet to help learning needs, specifically to teach in science, history, and language subjects. One of the learning resources is the mobile device. This device has many advantages, including a flexible and open learning system, as well as its use certainly requires specific characteristics, such as students' thinking ability. Teachers should develop tutoring skills according to students' needs, characteristics of learning material, and the basic capital of students.

It is necessary to analyze the supporting factors for the implementation of online learning designs, using a mobile device. The first step in developing models and approaches for creating learning designs is to conduct a need analysis. In terms of student characteristics, the entry behaviour and learning styles are factors supporting the development of online learning design [5]. Many Indonesian schools have implemented a similar system based on WhatsApp groups. The domain activities carried out by students include reading educational materials and completing online assignments [6][7]. Meanwhile, after one year of online learning, research shows that the outcomes are still poor. This is because, students are not trained to develop their reasoning power in problem-solving and applying concepts grasped into real-life situations. This indicates their critical thinking skills do not develop properly [8][10]. The ability to think critically and integrate relevant concepts are needed very much in thematic learning. Therefore, there is a need for an integrated thematic approach that incorporates material from various fields of research [10][11]. This is carried out with students' development, particularly, those in the elementary school [12][13]. When students are taught separate subjects, it is difficult for them to learn holistically. Accordingly, it is necessary to integrate educational activities by involving all learning senses. The involvement of all senses in learning is optimized by using video and task tutorial features, animations, as well as exercises that are integrated into the learning development using mobile device.

To improve students' skills in integrated thematic learning, direct activities on reallife situations that help to think through learning experiences are required. One of the advantages of designed media concept using mobile device is the ability to present holistic learning at a particular stage.

Moreover, the prestige of students is greatly influenced by the learning experience designed by teachers. The learning experiences that demonstrate more connections with conceptual elements improve its process [14][15]. To be able to design mobile learning, 
based on the needs, it is necessary to analyze the factors that support the application in terms of students' aspect as targets of learning.

There are significant factors related to this research as explained below:

\subsection{Mobile learning using an authentic approach and real-world activities}

Currently, mobile devices are used to conduct online learning. Effective online learning is carried out using an authentic approach and real-world activities. This strategy is an interesting method of learning, where students assimilate information while engaging in activities that are relevant to their needs through utilizing technology [16]. It focuses on the activities associated with tasks in the real-world context [9]. These exercises are designed to help students develop good analytical and critical thinking skills, as well as problem-solving abilities based on their characteristics. Authentic learning brings the true concept to life in student educational activities [17]. Moreover, learning is engaged directly through this concept by optimizing the real-world interaction process [4] [17][18]. This model is well-designed and as a result, students have practical knowledge and the ability to master competencies as a whole, which are applied in real-world. During implementation, teachers strive to design learning based on actual situations. The online learning using an authentic approach and real-world activities is achieved with a variety of tools, such as laptops, cell phones, and computers. The materials are equipped with interactive multimedia and e-modules. In interactive multimedia, learning videos and interactive figures are used, and the activities are likely completed by students at home with their parents.

\subsection{Entry behaviour and learning styles using mobile device}

Entry Behaviour is a skill acquired by students, prior to the planned acquisition of new knowledge [19]. Teachers seek to facilitate students in obtaining the final ability based on the entry behaviour, attained by them during the learning process [20]. In mobile learning, literacy ability is important [21], as students access a variety of resources through mobile device [22]. In addition, while creating learning designs, entry behaviour is important to be considered. It is also necessary to pay attention to the concept while developing online learning designs with authentic approaches and real-world activities [11]. The test methods are used to determine the students' entry behaviour cognitively, affectively, and psychomotorly. To establish this in mobile learning, online tests with applications are designed.

Another factor considered in the development of mobile learning is the students' learning style [23], which is related to how they assimilate information. In general, it is divided into 3 types, namely visual, auditory, and kinesthetic [11]. Authentic learning is associated with real-world activities carried out by students. In addition, this learning combines visual and auditory-kinesthetic activities because to obtain certain skills, educational activities are often required [24][25][26].

Based on the discussion above, this research aims to determine the supporting factors of online learning design application, using mobile learning with authentic approaches and real-world activities for elementary school students. This supporting 
factor is the crucial one to be analyzed as a basis for developing mobile learning design. The implementation encompasses the thinking characteristics at the elementary school level, initial ability level of students that are taught with conventional learning and its modalities.

The following questions which were answered include 1) How is thinking ability of the elementary school students? 2). How are their initial abilities? 3). What is the dominant learning style for students (which is implemented using mobile device)?

There are 35 literature reviews covered in this research. This literature was selected because it provided a comprehensive overview of the current, relevant, and comprehensive publications related to the research questions. In this literature review, the analysis, synthesis, and critical evaluation to create a clear picture of the research's theme was conducted.

\section{Methodology}

\subsection{Research design}

This research used a quantitative approach where a non-experimental survey design was used for the blueprint. A survey system allows user to summarize the aspects of a different group, or measures respondent attitude towards a particular issue. As a result, the cross-sectional survey design is being used to determine the existing insights or behaviours of a group at the designated point and time.

\subsection{Research procedure}

The participants were elementary school students with sample size of 26 homogeneous and normally distributed. Moreover, the data collection instruments were in the form of a questionnaire and test sheet. Students were given valid and reliable questionnaires to fill out and a test sheet to collect information about their characteristics, as well as learning styles and entry behaviour, respectively. Observation was used to obtain the knowledge of the students' traits and the data on initial characteristics were then analyzed. Furthermore, to obtain accurate results, the details on learning styles and entry behaviour were processed with factorial analysis and SmartPLS application. It was intended to obtain factors influencing data of online learning design with mobile device.

\section{$3 \quad$ Research results}

\subsection{Students' cognitive thinking ability}

Based on the research questions, the characteristics of students' cognitive thinking as a supporting factor for the implementation of the mobile device in learning process were observed from the logical and concrete thinking aspects of students. The logical and concrete thinking were obtained from a questionnaire given to students, relating to their ability to analyze and formulate solutions to the problems encountered. 
The results of the students' questionnaire analysis in terms of logical and concrete thinking skills were clearly shown in the following figure.

\section{Logical and Concrete Tinking}

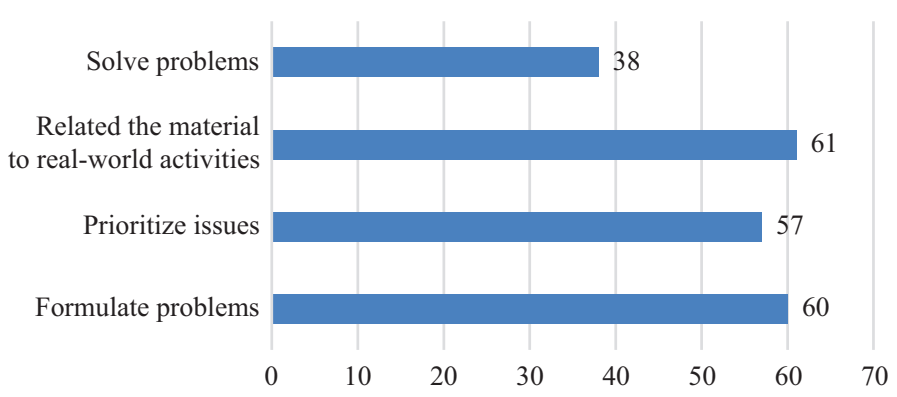

Fig. 1. Analysis of logical and concrete thinking

Based on the figure above, student's concrete thinking ability is strong, with an average percentage of more than $50 \%$. They formulate problems, prioritize issues, and relate the material to the real-world activities. However, these students' potential need to be improved optimally in online learning design. The two characteristics of logical and concrete thinking concepts need to be considered in designing online learning by using mobile device. When the average ability possessed by students is above $50 \%$, it means that the problem analysis and case research are crucial in learning design, in order to improve and train students' thinking skills.

\subsection{Initial ability}

The student's initial ability refers to the level of the knowledge obtained at the early stages of learning. The data were obtained by conducting an initial pre-test questions given to student. The questions covered three subjects such as Language, Science, Cultural Arts, and Crafts. The subjects had quite specific characteristics in terms of science, in order to analyze the initial abilities possessed by students in the subject. These observations were taken into consideration in developing multimedia-based mobile learning. The characteristics of the selected learning materials supported the development of other abilities. Language subject was the basis for students to be able to follow other subject matter. This encompasses reading, writing, listening, and presenting skills which were the basis for self-development in any other materials. Furthermore, Science subjects had specific characteristics in optimizing students' abilities in certain field, exploring a concept in formulating problems, collecting data, and concluding the issues. Art and culture subjects provided students to develop creativity values and psychomotor domain. The data showed the average score of students on the three subjects above and below $50 \%$.

Additionally, data of students' entry behaviour was gathered through pretest questions. The thematic learning is used in the Indonesian curriculum and many subjects are combined into certain themes. According to the pretest results, the percentage of 
students that completed the test were $45 \%$ in Indonesian language, $32 \%$ in science, and $50 \%$ in Arts, Culture and Crafts (SBDP). Teachers determines the learning method by observing students' entry behaviour. For more details, the pretest results were displayed in the following table:

Table 1. Data of students initial ability

\begin{tabular}{|l|c|l|c|c|l|}
\hline No & Total Students & \multicolumn{1}{|c|}{ Subjects } & Average Score & Percentage & \multicolumn{1}{|c|}{ Description } \\
\hline 1 & 26 & $\begin{array}{l}\text { Indonesian } \\
\text { Language }\end{array}$ & 73 & $45 \%$ & $\begin{array}{l}\text { Below completeness } \\
\text { standard }\end{array}$ \\
\hline 2 & 26 & Science & 63 & $32 \%$ & $\begin{array}{l}\text { Below completeness } \\
\text { standard }\end{array}$ \\
\hline 3 & 26 & $\begin{array}{l}\text { Arts, Culture and } \\
\text { Crafts (SBDP) }\end{array}$ & 75 & $50 \%$ & $\begin{array}{l}\text { Below completeness } \\
\text { standard }\end{array}$ \\
\hline
\end{tabular}

Based on the table above, average student completion rate is below $50 \%$, indicating very low. This was because students tend to only complete assignments without fully understanding the material. The higher completeness in the SBDP was because the questions asked tend to be rote, therefore, students obtain their answers by searching the internet or asking their parents. The low entry behaviour drives the need for authentic approaches and real-world activities using mobile learning-based multimedia.

\subsection{Student's learning style}

Learning style is the key element to be analyzed in designing mobile learning-based multimedia. The concept of multimedia is a combination of the whole student's learning styles. The variety of media presented in series and accessible on a smartphone needs to focus on student's learning styles and produce meaningful learning design. There are three learning styles, namely visual, audio, and audio-visual. The questionnaires that encompass students' behaviour and activities were used for data collection.

Table 2. Visual learning style

\begin{tabular}{|l|l|c|}
\hline \multicolumn{1}{|c|}{ No } & \multicolumn{1}{|c|}{ Indicator } & Percentage \\
\hline 1 & I like to learn by reading the teachers' instructions & $61 \%$ \\
\hline 2 & I prefer to learn by observing concept maps & $65 \%$ \\
\hline 3 & I enjoy learning by watching videos shown by teachers in front of the class & $57 \%$ \\
\hline
\end{tabular}

According to the data above, the factors that influence authentic learning and real world activities include the visual learning style, in which students prefer to read the teachers' instructions, observe concept maps, and enjoy learning through watching videos. Based on the questionnaire distributed, the following information was obtained: 
Table 3. Auditory learning style

\begin{tabular}{|l|l|c|}
\hline \multicolumn{1}{|c|}{ No } & \multicolumn{1}{|c|}{ Indicator } & Percentage \\
\hline 1 & I prefer to play than watch television & $50 \%$ \\
\hline 2 & I like listening to the teachers' explanation & $50 \%$ \\
\hline 3 & I like to do instructions directly from teachers or parents & $50 \%$ \\
\hline 4 & I feel disturbed if I study in a noisy environment & $57 \%$ \\
\hline 5 & I like listening to learning audio & $53 \%$ \\
\hline 6 & I like to discuss and learn with my parents or other people & $65 \%$ \\
\hline
\end{tabular}

From the data presented above, the most important factor in the auditory learning style is that students enjoy listening to educational audio, as well as discussing and gaining information with their parents or other people.

Table 4. Meaningful learning

\begin{tabular}{|l|l|c|}
\hline \multicolumn{1}{|c|}{ No } & \multicolumn{1}{|c|}{ Indicator } & Percentage \\
\hline 1 & I understand the material presented with a concept map & $61 \%$ \\
\hline 2 & I like learning with real activities at home and school & $53 \%$ \\
\hline 3 & I like the teachers' explanation & $50 \%$ \\
\hline 4 & I like the material presented with videos, figures, or graphics & $65 \%$ \\
\hline 5 & I like the material presented with relation to daily life & $61 \%$ \\
\hline
\end{tabular}

Meaningful learning is defined as a concept that connects the newly acquired information to the relevant, in a cognitive structure. It is closely related to authentic approaches created by teachers and applying them into the real world activities. According to the questionnaire, the supporting factors for meaningful learning are as follows: 1) learning presented with concept maps, 2) academic materials associated with videos, figures, and graphics to support students learning, 3) studying with friends or parents, resulting in scaffolding activities or providing assistance to students, and 4) activities designed are relevant to the daily life affairs, making them more meaningful for students.

To identify the predominant factors in the preparation of authentic learning designs and real world activities, the validity and reliability tests were performed: 
Table 5. Questionnaire validity test

\begin{tabular}{|l|l|}
\hline \multicolumn{1}{|c|}{ Learning Style } & Indicator Validity \\
\hline Auditory Skill & 0.740 \\
\hline A1 & 0.719 \\
\hline A2 & 0.630 \\
\hline A3 & 0.732 \\
\hline A4 & 0.771 \\
\hline A5 & 0.858 \\
\hline A6 & \\
\hline Visual Skill & 0.880 \\
\hline V1 & 0.828 \\
\hline V2 & 0.847 \\
\hline V3 & \\
\hline Meaningful Skill & 0.796 \\
\hline K1 & 0.792 \\
\hline K2 & 0.737 \\
\hline K3 & 0.751 \\
\hline K4 & 0.735 \\
\hline K5 & \\
\hline
\end{tabular}

Based on the data presented above, the questionnaire distributed to students was valid, with indicators scoring greater than 0.600 . Furthermore, the questionnaire's reliability was examined and the following information was obtained:

Table 6. Questionnaire's reliability test

\begin{tabular}{|l|c|c|c|c|}
\hline & Cronbach's Alpha & Rho_A & Composite Reliability & Average \\
\hline Auditory Skill & 0.838 & 0.846 & 0.881 & 0.554 \\
\hline Meaningful Learning & 0.820 & 0.823 & 0.874 & 0.581 \\
\hline Visual Skill & 0.817 & 0.850 & 0.888 & 0.726 \\
\hline
\end{tabular}

As shown in the table, the questionnaire was deemed reliable with the Cronbach's Alpha value of above 0.7 , and the composite Reliability value greater than 0.7 . The questionnaire is reliable, meaning that it produces consistent results while administered to the respondent multiple times.

Furthermore, the data were processed using a factor analysis model, yielding the following results:

Table 7. Factor analysis model

\begin{tabular}{|l|c|c|c|c|c|}
\hline & Original & Sample & Standard Deviation & T-Statistic & P Values \\
\hline Auditory Skill & 0.714 & 0.717 & 0.110 & 6.463 & 0.000 \\
\hline Visual Skill & 0.274 & 0.273 & 0.119 & 2.308 & 0.021 \\
\hline
\end{tabular}


According to the data presented above, the T-Statistic value, for each category, namely auditory and visual skills, is greater than the T-table of 1.70814 . However, the auditory learning style, with a $\mathrm{T}$ count of 6,463 is one of the factors that most strongly influence meaningful learning.

Furthermore, an analysis of the relationship between each factor was performed as follows:

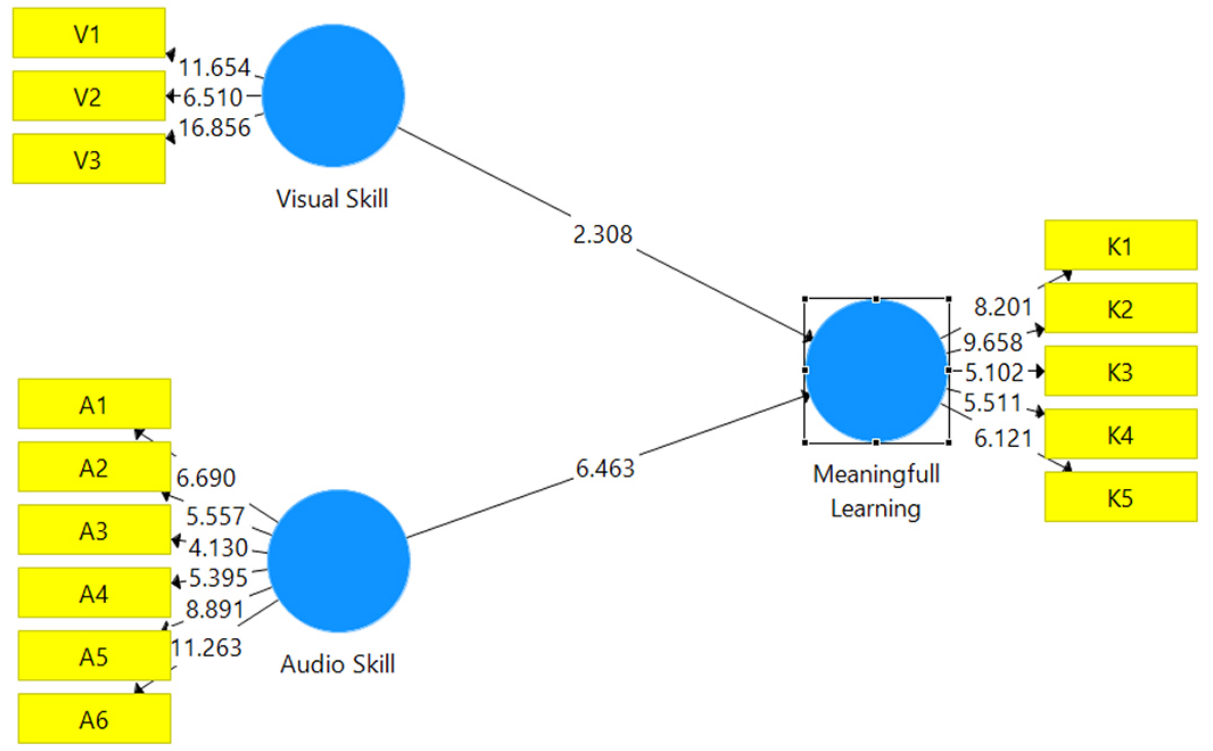

Fig. 2. Loading factors of indicators supporting meaningful learning

According to the loading factor above, the most dominant indicator in the visual skill is that, students are happy when teachers give learning instructions, and they enjoy watching presented educational videos. This is the relevant activity with mobile learning-based multimedia feature to engage all students in the whole activities. Furthermore, the predominant point in auditory skill activities is carrying out physical tasks, studying with friends and parents, because there are discussions and activities, such as listening to opinions. The most prominent indicators of meaningful learning are that, students prefer to learn using concept maps, through videos, figures, or graphics, and by using materials associated with daily life activities.

\section{Discussion}

The development of mobile learning-based multimedia is a crucial aspect of interest and needs to be developed, because it considers more supporting factors. The first factor is the students' characteristics cognitive thinking, and the results showed that it had developed very well, and had shown above $60 \%$, starting from creating problem formulations, determining priorities, linking materials with relevant conditions, and finding 
issues sequences. This ability is the essential element in the development of mobile learning-based multimedia using an authentic learning approach and real-world activities. The mobile learning-based multimedia provides a number of academic resources which are presented systematically, and students are able to select the material provided, in relation to the competency level they aimed to achieve [27]. The thinking logic and concrete ability play the key role in acquiring knowledge in the digital era. Meanwhile, learning resources are accessible on the internet and it requires good cognitive thinking and literacy skills to support learning activities.

This research also obtained data concerning the initial ability level of students in learning process. It showed low level for the subjects of Language, Science, Arts and Culture. After further observation, learning process required media and fun resources as supporting characteristic of effective learning. The low initial ability obtained by students was due to dense course load and less-mastering when it was taught conventionally. The data of students' initial abilities were obtained through the conventional learning process, and there was no multimedia used. Material characteristics of Language, Science and Cultural Arts subjects were made up of large and dense course load as a result of learning projects that required logical and concrete cognitive thinking abilities. The use of mobile learning-based multimedia required the ability to formulate, solve, and conclude issues. Meanwhile, it is necessary to design mobile learning-based multimedia equipped with assignments, case analysis, and learning videos to be analyzed by students. The use of multimedia helps to increase students' motivation, reading skills, and independence in learning [28].

The factors that support mobile device are closely related to meaningful learning, which involves auditory and visual abilities. These activities were created for mobile device by utilizing online modules and videos. Many factors were discovered as a result of the research, including the fact that mobile device is performed using concept maps, through videos, figures or graphics, and materials associated with daily life activities. The use of mobile device is supported by the creativity possessed by students, in order to learn more optimally, even though they are at home [29].

Online learning is designed using videos, in which students instantly follow at home. In this case, the use of mobile learning strongly supports these activities which are carried out directly and in real-time [24]. Mobile learning allows students to gather knowledge from various sources and enabling the production of more meaningful learning [30]. In addition, since students are known to be the digital native generation, this type of learning should be developed from the age of basic education [31]. This model is used anywhere with a variety of problem sources to increase social interaction in the 21 st century and assists students in actively solving problems in the real world contexts [31][32].

The findings are found to be relevant to teachers and learning designers, in creating authentic approaches and real-world activities, using mobile learning applications [33]. The authentic learning should be presented using a concept map, for the clarity of the activities and links in the educational material presented by teachers [26]. One of the benefits of mobile learning is that, students understand the entire concept of the information, which gives them meaning [34], [35]. In mobile learning, one of the supporting factors is the media, in the form of digital video [36], [35], [37]. 


\section{Conclusion}

Based on the results and discussion, it is concluded that: 1) students have developed logical and concrete thinking ability, however, they still achieved low level in the academic work, since conventional approach has not been implemented, and 2) the initial learning abilities of students were low. Furthermore, some key elements in learning styles, include providing concept map at the beginning of learning, using videos, figures and graphics, selecting real and familiar materials, which are known to support academic process. It is recommended for teachers or learning designers to optimize and take advantage of multimedia features, accessible online-materials, and learning applications on the internet, as supporting factors for effective academic work.

\section{Acknowledgment}

The author is grateful to the Institute for Research and Community Service (LP2M) of UNP, Padang State University, for funding this research under contract number 961/ UN35.13/LT/2021 and to the Institute for carrying out an ethical test that has been reviewed and authorized by the ethic committee.

\section{$7 \quad$ References}

[1] S. Poultsakis, S. Papadakis, M. Kalogiannakis, and S. Psycharis, "The Management of Digital Learning Objects of Natural Sciences and Digital Experiment Simulation Tools by Teachers," Adv. Mob. Learn. Educ. Res., vol. 1, no. 2, pp. 58-71, 2021, doi: https://doi. org/10.25082/AMLER.2021.02.002

[2] T. Karakose, R. Yirci, and S. Papadakis, "Exploring the Interrelationship between Covid-19 Phobia, Work-Family Conflict, Family-Work Conflict, and Life Satisfaction among School Administrators for Advancing Sustainable Management," Sustain., vol. 13, no. 15, 2021, doi: https://doi.org/10.3390/su13158654

[3] M. Bektas, "Examining the Teacher Candidates' Metaphorical Perceptions Related to the Notion of Authentic Learning," Int. Online J. Educ. Sci., vol. 11, no. 2, pp. 81-99, 2019, doi: https://doi.org/10.15345/iojes.2019.02.006

[4] N. Busadeea and P. Laosinchaib, "Authentic Problems in High School Probability Lesson: Putting Research into Practice,” Procedia - Soc. Behav. Sci., vol. 93, pp. 2043-2047, 2013, doi: https://doi.org/10.1016/j.sbspro.2013.10.162

[5] N. Dabbagh and C. Williams Blijd, "Students' Perceptions of Their Learning Experiences in an Authentic Instructional Design Context," Interdiscip. J. Probl. Learn., vol. 4, no. 1, pp. 2-13, 2010, doi: https://doi.org/10.7771/1541-5015.1092

[6] A. H. Rency Riwayanti, "Development of Character Education-Based Thematic Learning Modules in Grade V Elementary School," J. Basicedu, vol. 3, no. 2, p. 8, 2019 [Online]. Available: https://jbasic.org/index.php/basicedu

[7] A. A. S. Hidayati, "Flipped Classroom Strategy Oriented E-Module Development on Computer Network Learning," vol. 1, no. 3, pp. 1-9, 2021.

[8] N. Gurjar, "Leveraging Social Networks for Authentic Learning in Distance Learning Teacher Education," TechTrends, vol. 64, no. 4, pp. 666-677, 2020, doi: https://doi. org $/ 10.1007 / \mathrm{s} 11528-020-00510-7$ 
[9] T. A. Roman, M. Callison, R. D. Myers, and A. H. Berry, "Facilitating Authentic Learning Experiences in Distance Education: Embedding Research-Based Practices into an Online Peer Feedback Tool," TechTrends, vol. 64, no. 4, pp. 591-605, 2020, doi: https://doi. org/10.1007/s11528-020-00496-2

[10] M. Azizah, J. Sulianto, and N. Cintang, "Analysis of Critical Thinking Skills for Elementary School Students in Curriculum Mathematics Learning, 2013," J. Penelit. PendidikanA A, vol. 35, no. 1, pp. 61-70, 2018, doi: https://doi.org/10.15294/jpp.v35i1.13529

[11] D. P. Sari and A. Hidayati, "Effect of PJBL Model and Premery Knowledge on Critical Thingkin Skills of Grade IV Students of Kartika Elementery School 1-11 Kota Padang," vol. 1, no. 1, pp. 205-210, 2018, doi: https://doi.org/10.24036/ijeds.vli1.56

[12] A. Hidayati, "Analysis of the Factors Affecting the Effectiveness of Character-based Instructional Video Implementation to Early Childhood Education in Padang," J. Couns. Educ. Technol., vol. 1, no. 1, pp. 14-17, 2018, doi: https://doi.org/10.32698/051

[13] J. Stefaniak, "A Systems View of Supporting the Transfer of Learning through E-Service-Learning Experiences in Real-World Contexts," TechTrends, vol. 64, no. 4, pp. 561-569, 2020, doi: https://doi.org/10.1007/s11528-020-00487-3

[14] A. Hidayati, R. Efendi, and A. Saputra, "The Quality of Digital Literation Early Childhood Education Teachers Based on UNESCO Standards," Int. J. Sci. Technol. Res., vol. 9, no. 3, pp. 3514-3517, 2020.

[15] A. P. Muji et al., "The Effectiveness of the Implementation of Lesson Plans Based on Entrepreneurial Values in the Kindergarten," Int. J. Sci. Technol. Res., vol. 8, no. 12, pp. 121-128, 2019.

[16] Y. Zidoun, R. Dehbi, M. Talea, and F. El Arroum, "Designing a Theoretical Integration Framework for Mobile Learning," Int. J. Interact. Mob. Technol., no. 12, pp. 152-170, 2019, doi: https://doi.org/10.3991/ijim.v13i12.10841

[17] J. L. Devine, K. S. Bourgault, and R. N. Schwartz, "Using the Online Capstone Experience to Support Authentic Learning," TechTrends, vol. 64, no. 4, pp. 606-615, 2020, doi: https:// doi.org/10.1007/s11528-020-00516-1

[18] C. Marull and S. Kumar, "Authentic Language Learning through Telecollaboration in Online Courses," TechTrends, vol. 64, no. 4, pp. 628-635, 2020, doi: https://doi.org/10.1007/ s11528-020-00488-2

[19] M. Masnia, "Application of the Group Investigation Learning Model to Improve Student Learning Outcomes," APOTEMA J. Progr. Stud. Pendidik. Mat., vol. 2, no. 2, pp. 45-51, 2016, doi: https://doi.org/10.31597/ja.v2i2.116

[20] A. H. Febriannno Suryana, "Needs Analysis of the Development of Cooperative Project Based Learning Models in the Digital Age," vol. 1, no. 1, pp. 13-19, 2020 [Online]. Available: http://ejournal.undhari.ac.id/index.php/jveit JVEIT

[21] A. Permanasari, "STEM Education: Innovation in Science Learning," Pros. Semin. Nas. Pendidik. Sains, pp. 2016-23, 2016.

[22] K. Y. S. Putri, Z. Bin Abdullah, E. Nugrahaeni, R. Darmawan, and Latifa, "Learning Management Strategy of Communication Studies Through Blended Learning in Higher Education," Int. J. Interact. Mob. Technol., vol. 14, no. 16, pp. 117-132, 2020, doi: https://doi. org/10.3991/ijim.v14i16.15725

[23] S. Loucks and G. Ozogul, "Preparing Business Students for a Distributed Workforce and Global Business Environment: Gaining Virtual Leadership Skills in an Authentic Context," TechTrends, vol. 64, no. 4, pp. 655-665, 2020, doi: https://doi.org/10.1007/ s11528-020-00513-4

[24] I. Kadek Suartama, P. Setyosari, Sulthoni, and S. Ulfa, "Development of Ubiquitous Learning Environment Based on Moodle Learning Management System," Int. J. Interact. Mob. Technol., vol. 14, no. 4, pp. 182-204, 2020, doi: https://doi.org/10.3991/ijim.v14i14.11775 
[25] A. Bentri, A. Hidayati, and U. Rahmi, "The Problem Analysis in Applying Instrument of Authentic Assessment in 2013 Curriculum," Int. J. Sci. Res., vol. 5, no. 10, pp. 1008-1012, 2016.

[26] J. Herrington and L. Kervin, "Authentic Learning Supported by Technology: Ten Suggestions and Cases of Integration in Classrooms," EMI. Educ. Media Int., vol. 44, no. 3, pp. 219-236, 2007, doi: https://doi.org/10.1080/09523980701491666

[27] B. Budiamai, K. Komarudin, N. Nuruddin, and C. Kustandi, "Learning Design on Social Studies Through Digital Book in Senior High School," Int. J. Interact. Mob. Technol., vol. 15, no. 9, pp. 154-166, 2021, doi: https://doi.org/10.3991/ijim.v15i09.18435

[28] H. F. Hanafi et al., "Utilizing Animal Characters of a Mobile Augmented Reality (AR) Reading Kit to Improve Preschoolers' Reading Skills, Motivation, and Self-Learning: An Initial Study,” Int. J. Interact. Mob. Technol., vol. 15, no. 24, pp. 94-107, 2021. https://doi. org/10.3991/ijim.v15i24.26673

[29] A. Badawood and H. Albadri, "Technology Based Model of a Mobile Knowledge as a Service to Facilitate Education Community," Int. J. Interact. Mob. Technol., vol. 15, no. 24, pp. 49-60, 2021. https://doi.org/10.3991/ijim.v15i24.27335

[30] O. V. Galustyan, A. P. Smetannikov, I. G. Kolbaya, G. S. Palchikova, D. V. Galigorov, and O. B. Mazkina, "Application of Mobile Technologies for the Formation of Analytical Competence of Future Specialists," Int. J. Interact. Mob. Technol., vol. 14, no. 2, pp. 242-249, 2020, doi: https://doi.org/10.3991/ijim.v14i02.11658

[31] I. Damyanov and N. Tsankov, "Mobile Apps in Daily Learning Activities," Int. J. Interact. Mob. Technol., vol. 12, no. 6, pp. 133-140, 2018, doi: https://doi.org/10.3991/ijim. v12i6.9659

[32] N. Rungrangtanapol and J. Khlaisang, "Development of a Teaching Model in Virtual Learning Environment to Enhance Computational Competencies in the 21st Century," Int. J. Interact. Mob. Technol., vol. 15, no. 13, p. 93, 2021, doi: https://doi.org/10.3991/ijim. v15i13.21791

[33] H. Hardika, E. N. Aisyah, K. M. Raharjo, and D. U. Soraya, "Transformation the Meaning of Learning for Millennial Generation on Digital Era," Int. J. Interact. Mob. Technol., vol. 14, no. 12, pp. 69-81, 2020, doi: https://doi.org/10.3991/ijim.v14i12.15579

[34] K. Lee, "Autoethnography as an Authentic Learning Activity in Online Doctoral Education: an Integrated Approach to Authentic Learning," TechTrends, vol. 64, no. 4, pp. 570-580, 2020, doi: https://doi.org/10.1007/s11528-020-00508-1

[35] A. Leichsenring, "Authentic Learning for Elementary Students through e-Learning," Educ. Artic., vol. 1, no. 1, pp. 1-5, 2013.

[36] A. Hidayati, W. Amilia, and M. F. Amsal, "Need Analysis of Media Video Development for Character Education at Early Childhood Education in Padang," vol. 169, no. Icece 2017, pp. 108-110, 2018, doi: https://doi.org/10.2991/icece-17.2018.26

[37] M. Kearney, S. Schuck, and F. Education, "Authentic Learning Through the Use of Digital Video," History, no. May, pp. 1-7, 2002.

\section{Authors}

Abna Hidayati is member of the International Association of Online Engineering (IAOE), Kirchengasse 10/200, 1070 Wien, Austria. He is a lecture and researcher in the Department of Curriculum and Educational Technology, Faculty of Education, Universitas Negeri Padang, Indonesia. Fields of expertise include curriculum, education and technology of education. Orcid ID: 0000-0002-6165-8266, Scopus ID: $\underline{57202292083}$ 
Alwen Bentri is a professor and researcher in the Department of Curriculum and Educational Technology, Faculty of Education, Universitas Negeri Padang, Indonesia. Fields of expertise include curriculum, education and technology of education. Orcid ID: 0000-0002-8358-3867, Scopus ID: $\underline{57198816332}$

Eldarni is a lecture and researcher in the Department of Curriculum and Educational Technology, Faculty of Education, Universitas Negeri Padang, Indonesia. Fields of expertise include education and technology of education.

Article submitted 2021-08-26. Resubmitted 2021-11-19. Final acceptance 2022-01-05. Final version published as submitted by the authors. 